\title{
Juvenile arthritis management in less resourced countries (JAMLess): consensus recommendations from the Cradle of Humankind
}

\author{
Christiaan Scott ${ }^{1}$ (D) $\cdot$ Mercedes Chan ${ }^{2} \cdot$ Waheba Slamang ${ }^{1} \cdot$ Lawrence Okong'o $^{3} \cdot$ Ross Petty $^{4} \cdot$ Ronald M. Laxer $^{5}$. \\ María-Martha Katsicas ${ }^{6}$. Francis Fredrick ${ }^{7}$. James Chipeta ${ }^{8} \cdot$ Gail Faller $^{9} \cdot$ Gecilmara Pileggi $^{10}$. \\ Claudia Saad-Magalhaes ${ }^{11}$. Carine Wouters ${ }^{12} \cdot$ Helen E. Foster ${ }^{13} \cdot$ Raju Kubchandani ${ }^{14}$. Nicolino Ruperto ${ }^{15}$. \\ Ricardo Russo ${ }^{16}$
}

Received: 3 August 2018 / Revised: 3 September 2018 / Accepted: 16 September 2018

(C) International League of Associations for Rheumatology (ILAR) 2018

\begin{abstract}
Juvenile idiopathic arthritis (JIA) is the most prevalent chronic rheumatic disease in children and young people (CYP) and a major cause of pain and disability. The vast majority of the world's children and their families live in less resourced countries (LRCs) and face significant socioeconomic and healthcare challenges. Current recommendations for standards of care and treatment for children with JIA do not consider children living in less resourced countries. In order to develop appropriate recommendations for the care of CYP with JIA in less resourced countries a meeting of experienced pediatric rheumatologists from less resourced countries was convened with additional input from a steering group of international pediatric rheumatologists with experience in developing recommendations and standards of care for JIA. Following a needs assessment survey of healthcare workers caring for CYP with JIA in LRC, a literature review was carried out and management recommendations formulated using Delphi technique and a final consensus conference. Responses from the needs assessment were received from 121/483 (25\%) practitioners from 25/ $49(51 \%)$ less resourced countries. From these responses, the initial 84 recommendations were refined and expanded through a series of 3 online Delphi rounds. A final list of 90 recommendations was proposed for evaluation. Evidence for each statement was reviewed, graded, and presented to the consensus group. The degree of consensus, level of agreement, and level of evidence for these recommendations are reported. Recommendations arrived at by consensus for CYP with JIA in less resourced countries cover 5 themes: (1) diagnosis, (2) referral and monitoring, (3) education and training, (4) advocacy and networks, and (5) research. Thirty-five statements were drafted. All but one statement achieved $100 \%$ consensus. The body of published evidence was small and the quality of evidence available for critical appraisal was low. Our recommendations offer novel insights and present consensus-based strategies for the management of JIA in less resourced countries. The emphasis on communicable and endemic

Christiaan Scott

chris.scott@uct.ac.za

1 Department of Pediatrics and Child Health, Room 515, ICH building, Red Cross War Memorial Children's Hospital, University of Cape Town, Cape Town, Rondebosch 7700, South Africa

2 Department of Pediatrics, BC Children's Hospital, University of British Columbia, Vancouver, Canada

3 University of Nairobi, Nairobi, Kenya

4 Department of Pediatrics, University of British Columbia, Vancouver, Canada

5 The Hospital for Sick Children, University of Toronto, Toronto, Canada

6 Hospital de Pediatría Garrahan, Buenos Aires, Argentina

7 School of Medicine, Muhimbili University of Health and Allied Sciences, Dar es Salaam, Tanzania

8 Department of Paediatrics and Child Health, University of Zambia School of Medicine, Lusaka, Zambia

9 Wits Donald Gordon Medical Centre, University of the Witwatersrand, Johannesburg, South Africa

10 Clinical Research Center of Ribeirão Preto Medical School, University of Sao Paulo, Sao Paulo, Brazil

11 Division of Pediatric Rheumatology, Sao Paulo State University, Sao Paulo, Brazil

12 Department of Microbiology and Immunology and Pediatric Rheumatology, University Hospitals Leuven, Leuven, Belgium

13 Great North Children's Hospital, Newcastle University, Newcastle, UK

14 Department of Pediatrics, Jaslok Hospital, Mumbai, India

15 Istituto Giannina Gaslini, Clinica Pediatrica e Reumatologia, PRINTO, Genoa, Italy

16 Hospital de Pediatría Garrahan, Buenos Aires, Argentina
\end{abstract}


diseases influencing the diagnosis and treatment of JIA serves as a valuable addition to existing JIA guidelines. With increasing globalization, these recommendations as a whole provide educational and clinical utility for clinicians worldwide. The low evidence base for our recommendations reflects a shortage of research specific to less resourced countries and serves as an impetus for further inquiry towards optimizing care for children with JIA around the world.

Keywords Developing world $\cdot$ Juvenile idiopathic arthritis $\cdot$ Management $\cdot$ Recommendations

\section{Introduction}

Juvenile idiopathic arthritis (JIA), the most prevalent chronic rheumatic disease in children and young people (CYP), is a major cause of musculoskeletal disability [1]. Less resourced countries(LRC) face a unique set of challenges in caring for CYP with JIA, which limit the ability to deliver high-quality care to patients with JIA and their families. These challenges include a lack of trained pediatric rheumatologists or pediatricians, inadequate healthcare funding, restricted access to medications, poverty, lower levels of education, and a high burden of infectious disease. As a result, low or non-existent levels of priority and funding exist for non-communicable and rare diseases, including rheumatic conditions.

The extent of the disparity is illustrated by an estimate that in 2011, the USA, with $3 \%$ of the global overall disease burden, had access to $25 \%$ of global healthcare resources and $30 \%$ of healthcare workers. In contrast, sub-Saharan Africa, with $25 \%$ of the global burden of disease, had access to $3 \%$ of healthcare resources and $1 \%$ of healthcare workers. [2] Infectious diseases constitute a large proportion of the burden in these countries, and it has been estimated that nearly $50 \%$ of mortality for children age 5-15 in these settings is caused by infection. [3] The education and already meager healthcare resources that do exist are focused on the management of infections. [4] This, and other factors such as national healthcare distribution, cultural practices, reliance on traditional healthcare practices, poverty, large travel distances, and social and political challenges contribute to the scarcity of resources and expertise available to manage noncommunicable diseases. In 2011, it was estimated that 6-7 million children were living with rheumatic disease worldwide; $80 \%$ of these children live in Asia and Africa. [5] With the reported prevalence of JIA being 1-4 in 1000 children $[6,7]$ and current UNICEF estimates of the number of children to be 2.2 billion [8], there are likely to be 2 to 8 million children living with arthritis; yet, there is a shortfall of pediatric rheumatologists in the highly populated countries that need them the most. Only four of the nine Southeast Asian countries have pediatric rheumatologists, ranging from 3 per 30 million people in Malaysia to 4 per 65 million epople in Thailand [9]. Estimates from Latin America cite 1 pediatric rheumatologist per 4.1 million children from 2011, with subSaharan Africa having, at present, an estimated 10 pediatric rheumatologists for approximately 550 million children. With infectious diseases receiving the majority of healthcare funding in developing countries, rheumatology education and training, expertise, clinical supports, and resources for treating CYP with rheumatic disease, e.g., diagnostics, therapeutics, are severely lacking. $[10,11]$ A recent multinational epidemiological study which included less resourced countries affiliated with the Paediatric Rheumatology International Trials Organisation (PRINTO) [12] indicated that children with JIA in less resourced countries have higher rates of active disease and joint damage than their counterparts in developed nations; this study was unable to measure the status of children in less resourced countries where pediatric rheumatology care is not well developed. [13, 14]

Treatment guidelines for JIA that have been formulated in several countries are probably only applicable to a small portion of the world's children with JIA. Existing recommendations include those of the American College of Rheumatology (ACR), the guidelines of the British Society for Pediatric and Adolescent Rheumatology (BSPAR) Standards of Care, a position statement from the pediatric committee of the Canadian Rheumatology Association, the Australian Pediatric Rheumatology Group standards of care, recent International treat to target recommendations, and the European Union SHARE (Single Hub Access to RhEumatology) guidelines currently in preparation. [15-20] The distances that patients travel to access pediatric rheumatology healthcare; delayed diagnosis; endemic infections such as tuberculosis, malaria, and human immunodefieciency virus (HIV); poor monitoring facilities; and the poor access to biological therapies make the implementation of existing guidelines (all of which were devised in the resource-rich countries) extremely difficult in resource-challenged settings and with few appropriate alternatives. Randomized trials conducted in these countries are indeed referring essentially to methotrexate [21], while trials with biologics, even if conducted in some Latin American countries, are not available to the majority of the CYP in LRC. [22-28]

The aim of this project was to develop appropriate recommendations for the care of CYP with JIA in LRC, specifically addressing the unique challenges faced by CYP in these settings. The target audience for our work is all healthcare workers, including pediatric and adult rheumatologists, as well as pediatricians, health authority policy makers, 
education and training organizations, and others responsible for the care of CYP with JIA in less resourced countries. It is hoped that these recommendations will provide a framework to inform the clinical services and delivery of clinical care as well as education and training of the workforce and be a benchmark for strategy and implementation for improvement in the care of CYP with JIA.

\section{Methods}

The principal investigators (CS and RR), with funding from the International League of Associations for Rheumatology (ILAR), assembled a group of pediatric rheumatologists from less resourced countries. This included eight physicians from Argentina, Brazil, India, Kenya, South Africa, and Tanzania. In addition, a group of six pediatric rheumatologists with experience in the development of JIA guidelines from Belgium, Canada, Italy, and the United Kingdom were included. From this team, a core working group consisting of the principal investigators, two research officers (WS and LO), and two methodologists (MC and NR) was formed.

A needs assessment regarding management of JA was created around five themes identified as relevant to rheumatology in the developing world [29]: (1) patient management (diagnosis); (2) patient management (referral and monitoring; (3) education and training; (4) advocacy, networks, and policy; and (5) research. The survey (available in English and Spanish) was circulated electronically using REDCap electronic data capture tools hosted at the University of Alberta [30] to 483 PRINTO or self-identified healthcare practitioners (physicians and allied health professionals) managing JIA in 49 developing countries. Contacts for these individuals were derived from professional networks such as PRINTO and by posting on pediatric rheumatology listserve originating from McMaster University with a call to forward onto other individuals working in low-resource settings (manuscript in preparation).

Using the results of the needs assessment survey an initial list of recommendations was proposed and electronically circulated among the consensus group. These were refined and expanded through a series of online Delphi rounds. A final list of statements was proposed for evaluation. The core working group (CS, RR, MC, WS, CSM, LO), who held bimonthly tele-meetings for a year, embarked on a comprehensive literature review to examine evidence for each of the statements. Researchers used combinations of search terms around each of the previously identified themes and searched in PubMed and Scielo (Spanish and Portuguese). The working group selected the most appropriate papers for review and eliminated duplicates, finally including 188 papers out of 1590 screened. Selection criteria were specific for each statement. The core working group independently graded the selected papers on methodological quality, level of evidence, and strength of recommendation, according to Oxford levels of evidence (OCEBM Levels of Evidence Working Group. Oxford Centre for Evidence-Based Medicine. The Oxford 2011 Levels of Evidence. 2011). Discrepancies were resolved by discussion among the experts. Articles and their corresponding graded levels of evidence were compiled in a series of handbooks and circulated to all members of the consensus group for review before a 3-day final consensus conference at the Cradle of Humankind region, near Johannesburg, South Africa, in July 2017. At the final consensus conference, each statement was individually reviewed along with a summary of all the evidence. Each statement was analyzed and discussed using the nominal group technique (NGT) [31]. Recommendations were refined and voted on by 14 voting delegates (CS, RR, MC, WS, RML, RP, GF, CSM, GP, RK, FF, JC, HF, CW) with NR as non-voting NGT moderator. Statements were accepted upon achieving $\geq 80 \%$ agreement. Mean LOA score and standard deviation are reported. It was agreed that maintaining an emphasis on evidence-based therapies would best serve the advocacy and educational functions of the JAMLess guidelines and the long-term interest of our patients. This is reflected in our final selection of statements. A final level of agreement (LOA) score was allocated to each statement by each voting delegate, where 0 indicated absolute disagreement and 10 indicated absolute agreement.

\section{Results}

Responses from the needs assessment were received from $121 / 483(25 \%)$ practitioners from 25/49 (51\%) less resourced countries. From these responses, an initial 84 recommendations were proposed and electronically circulated among the expert group. These were refined and expanded on through a series of three online Delphi rounds. A final list of 90 statements was proposed for evaluation.

Statements were grouped as per the five themes identified in the needs assessment (manuscript in process): (1) management: diagnosis; (2) management: treatment, referral, and monitoring; (3) education and training; (4) advocacy and networks and policy; and (5) research. Overarching statements introduce and inform statements contextualized to specific themes. After re-wording and combining statements with multiple components but a similar root statement, a final list of 34 statements emerged. All statements except one achieved $100 \%$ consensus during the final conference (Table 1).

\section{Clinical management}

Our paper presents recommendations that address the effect of endemic and communicable diseases in masking the diagnosis of JIA. This represents a novel contribution to existing guidelines. In the era of climate change, increasingly accessible 
Table 1 The final list of evidence based and consensus driven recommendations for the management of Juvenile Idiopathic Arthritis in less resourced countries.

Clinical management

The diagnosis of JIA should be made following ILAR criteria [1] and exclude conditions

that may mimic JIA including, but not limited to:

- Malignancies, especially leukemia

- Constitutional bone and cartilage disorders

- Metabolic, endocrine, hematological and nutritional disorders

- Autoimmune and auto-inflammatory diseases

1. In endemic areas or with relevant travel history, the following diseases should be

considered in the differential diagnosis of JIA.

- Tuberculosis (TB) and TB reactive arthritis (Poncet's disease)

- Rheumatic fever and post-streptococcal arthritis

- Human Immunodeficiency Virus (HIV)

- Chikungunya

- Spirochete infection (Lyme, leptospirosis, syphilis)

2. JIA should be considered in the differential diagnosis for patients being presumptively treated for the following conditions (including but not limited to):

- Tuberculosis (TB) and TB reactive arthritis (Poncet's disease)

- Rheumatic fever and post-streptococcal arthritis

- HIV

- Chikungunya

- Spirochete infections (Lyme, leptospirosis, syphilis)

3. In endemic areas or with relevant travel history, the following diseases should be considered in the differential diagnosis of systemic JIA with or without macrophage activation syndrome(MAS).

- Malaria

- Typhoid

- Brucellosis

- Systemic fungal infection (e.g., histoplasmosis, blastomycosis)

- Arboviral infections (e.g., Dengue, Yellow Fever, Mayaro Virus)

- Parasitic infections (e.g., Leishmaniasis)

4. Systemic JIA (MAS) should be considered in the differential diagnosis for patients being presumptively treated for the following conditions (including but not limited to):

- Malaria

- Typhoid

- Brucellosis

- Systemic fungal infection (histoplasmosis, blastomycosis)

- Arboviral (Dengue, Yellow Fever, Mayaro Virus), Leishmaniosis, etc.

5. In children being treated as post-infectious or reactive arthritis secondary to specific gastrointestinal $^{\mathrm{a}}$ or genitourinary ${ }^{\mathrm{b}}$ pathogens, JIA should be considered with ongoing symptoms for more than 6 weeks.

6. In populations with high prevalence, sickle cell disease should be considered in the differential diagnosis of JIA.

Treatment, referral, and monitoring

The management of JIA is multidisciplinary, multi-professional and includes medical and non-medical approaches.

7. Where possible, inpatient and outpatient management of JIA should be

- Pediatric Rheumatologists

- Adult Rheumatologists

- Pediatricians

- General Practitioners

- Orthopedic Surgeons

- Nurses

- Physiotherapists

- Occupational Therapists

- Social Workers

- Dietitians 
Table 1 (continued)

- Psychologists

- Ophthalmologists

- Dentists

8. Telemedicine should be developed and encouraged to monitor children from remote areas after an initial diagnosis by a face-to-face meeting.

9. An age after which JIA patients should be seen by adult rheumatology providers should be discussed, agreed upon and put into practice by pediatric and adult institutions.

10. A 'multidisciplinary team approach' is the optimal way to manage JIA. Efforts to organize such a team should be carried out in all specialist centres.

11. When indicated, JIA patients should have timely access to joint injections using an appropriate steroid preparation. This should be performed by a rained clinician, using appropriate anesthesia (local, general, or inhaled).

12. There are recent recommendations and guidelines on the therapeutic management of JIA and this consensus group endorses their use [15-20]. Limited access due to availability and cost of biologics often hamper their initiation or sustained use. Methotrexate is an effective therapeutic agent and a component of all available international and national guidelines and recommendations and this consensus group strongly endorses its early use in JIA patients. There is insufficient evidence for the safety and efficacy of other lower cost synthetic drugs or their combinations in the treatment of JIA. The consensus group endorses the need for new international collaborative approaches to facilitate affordability and access to medicines with proven safety and efficacy.

13. All JIA patients should have regular uveitis screening as prescribed by international guidelines. [19, 65]

14. The use of drugs that affect the immune response can increase the risk of worsening pre-existing infections or the development of new and opportunistic infections. The following infections (including but not limited to) should be considered and managed before, during and after such therapies in patients with JIA. Local guidelines should be used where available:

- Tuberculosis (latent or active)

- HIV

- Hepatitis B and C

- Cytomegalovirus (CMV)

- Pneumocystis Jirovecii Pneumonia (PJP)

- Chickenpox/Zoster and other vaccine preventable diseases (e.g., Hepatitis A and B, Measles, Mumps, Rubella, Influenza)

- Systemic fungal infections

15. New patients with suspected inflammatory arthritis should be referred as soon as possible and ideally be seen by a pediatric rheumatologist. The first assessment should be within 4 weeks from the time of referral in order to optimize outcomes. In the absence of a pediatric rheumatologist, patients should be assessed by a clinician knowledgeable and skilled in caring for children and young people with rheumatic disorders who, ideally, is affiliated with an established rheumatology clinical network.

16. Unless contraindicated due to immunosuppressive therapy, all JIA patients should receive vaccinations as specified by their National Immunization Program(NIP), or, if unavailable, immunizations based on the CDC or WHO annual recommendations schedule. [77, 78]

17. When JIA patients are on immunosuppressive therapy, current specific immunization guidelines (e.g., EULAR ${ }^{\mathrm{a}}$ ) $[48,49]$ should be adapted to the local context, made available to the rheumatology clinical network and critically evaluated considering individual sociocultural, economic and region-specific contexts. 18. Catch-up immunizations should be provided before the start of any immunosuppression treatment, where possible, or effected during windows of opportunity. (Table 2)

19. Varicella vaccination should be considered for all JIA patients without clear evidence or history of previous infection or vaccination, prior to the start of immunosuppressive therapy. In areas where varicella vaccine is not available or part of the routine immunization schedule for children, national or international

$\begin{array}{llll}\mathrm{D} & 5 & 100 \% & 9.1 \pm 1.6 \\ 4 & \mathrm{C} & 100 \% & 9.2 \pm 1.1 \\ \mathrm{H} & \mathrm{C} & 100 \% & 9.7 \pm 0.8 \\ \mathrm{1b} & \mathrm{A} & 100 \% & 9.9 \pm 0.3 \\ & & & \\ 1 \mathrm{a} & \mathrm{A} & 100 \% & 9.6 \pm 1.2\end{array}$

$$
\text { C }
$$


guidelines for the management of exposure to varicella in an immune suppressed patient should be followed. Patients with signs of varicella should be promptly treated with antiviral therapy. Immunization or antiviral therapy should be considered for close contacts.

20. JIA patients with a positive PPD or Quantiferon test should receive appropriate prophylaxis for tuberculosis according to current national or international guidelines and in the following scenarios:

- At the start of biologic therapy

- When on biologic therapy and a previously negative PPD converts to positive at the mandatory annual TB screening.

- New exposure to TB

Education and training

To optimize care for JIA and other pediatric rheumatic diseases, training opportunities in pediatric rheumatology should ideally be available to health care workers in each country. Training programs for pediatric rheumatologists should be established in countries where access to adequate infrastructure, expertise and resources exist or through collaboration. Available syllabi and online training programs ${ }^{\mathrm{c}}$ could be used as a guide and adapted for local use. Educational resources should incorporate web-based tools, so as to reach more health care and allied health care professionals at all levels of training and practice. The content should ideally be developed and reviewed by a pediatric rheumatologist. Teaching should preferably be delivered by a clinician knowledgeable and skilled in caring for children with rheumatic disorders, ideally affiliated with an established rheumatology clinical network. Clinical practice and treatment recommendations should be made available to all members of the rheumatology network, critically evaluated and adapted for individual sociocultural, economic and region-specific contexts.

21. An introduction to JIA should be part of the undergraduate core curriculum in medical schools.

22. Joint examination should be an essential part of undergraduate clinical teaching.

23. Pediatric rheumatology should be a feature of all training programs for:

- Pediatricians

- Adult rheumatologists

24. JIA and related conditions should be a feature of all training programs for:

- Medical Doctors

- Orthopedic Surgeons

- Physical Medicine and Rehabilitation practitioners (Physiatry)

- Family Medicine/General Practitioners

- Radiologists

- Ophthalmologists

- Emergency Physicians

- General Internists

- Dentists

Allied Health Professionals

- Community Health Care Workers (e.g., Health Officers, etc.)

- Nurses

- Physiotherapists

- Occupational Therapists

- Podiatrists

25. JIA and related conditions should be a feature of all continuing education programs for:

- General Internists

- Orthopedic Surgeons

- Physical Medicine and Rehabilitation Practitioners (Physiatrists)

- Family Medicine/General Practitioners

- Radiologists

- Ophthalmologists

- Emergency Physicians

- Dentists

Allied Health Professionals

- Community Health Care Workers (e.g. Health Officers, etc.)

- Nurses

$\begin{array}{llll}5 & \mathrm{D} & 100 \% & 10 \\ 5 & \mathrm{D} & 100 \% & 10 \\ 5 & \mathrm{D} & 100 \% & 10 \\ & & & \\ 5 & \mathrm{D} & 100 \% & 9.5 \pm 0.9\end{array}$


Table 1 (continued)

Quality Strength Consensus Mean \pm SD level

of agreement

- Physiotherapists

- Occupational Therapists

- Podiatrists

26. Clinicians caring for patients with JIA and other rheumatic disorders should

be encouraged and enabled (e.g., University sponsorship, reducing conference costs,

bursaries, service coverage) to attend, organize and participate in relevant local, regional or international educational activities.

Advocacy, networks, and policy

Clinicians knowledgeable and skilled in caring for children and young people with rheumatic disorders and ideally affiliated with an established rheumatology clinical network should:

27. Encourage and support patients with JIA and their families to access appropriate educational and informational resources, e.g., print or online ${ }^{\mathrm{d}}$ as well as existing local and national patient organizations, for support and networking.

28. Encourage patients and their families to develop and participate in patient support groups.

29. Increase awareness of JIA through educational activities targeting teachers, educators and the general public.

30. Engage with policy makers and healthcare authorities to improve awareness of JIA and its impact on the healthcare system and patients and their families.

Research

Research is critical to enhancing the health of children with JIA.

31. Clinicians caring for patients with JIA should be encouraged and enabled to initiate, lead, participate in, present and publish their research.

32. Research training should be included in pediatric rheumatology training, to enable future pediatric rheumatologists to perform research.

33. Research should ideally be relevant to the local population. Research activities may include but are not limited to the following:

- Epidemiology

- Unmet local needs-healthcare and educational

- Disease burden and impact

- Models of healthcare delivery.

34. Collaboration with local, national and international research activities/ networks should be encouraged.

5

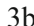

$3 b$

5

5

$3 b$

C

$100 \%$

$9.9 \pm 0.3$

$3 \mathrm{~b}$

C

$100 \%$

$9.9 \pm 0.3$

B

$100 \%$

$9.6 \pm 0.9$

B

$100 \%$

$9.8 \pm 0.6$

5

D

$100 \%$

$9.6 \pm 0.8$

5

D

$100 \%$

$9.6 \pm 0.9$

5

D

$100 \%$

10

D

$100 \%$

10

${ }^{a}$ E. Coli, Salmonella, Shigella, Campylobacter, Yersinia

${ }^{\mathrm{b}}$ Gonococcus, Chlamydia

${ }^{\mathrm{c}}$ The Royal Australasian College of Physicians: Pediatric and Child Health Division Advanced Training Curriculum for Rheumatology; The Royal College Of Physicians and Surgeons of Canada Objectives of Training in the Subspeciality of Adult and Pediatric Rheumatology; The Colleges of Medicine of South Africa Syllabus for Pediatric Rheumatology; The Royal College of Pediatrics and Child Health Curriculum for Pediatric Training: Pediatric Rheumatology; The American Board of Pediatrics Content Outline: Pediatric Rheumatology

${ }^{\mathrm{d}}$ www.printo.it

world travel and international migration, clinicians in both developed and developing nations must familiarize themselves with common mimics of arthritis stemming from infections previously thought to be relevant only in developing nations. Decreased global health expenditure, under-vaccination, and increasing health disparities further increase the burden of communicable diseases, some of which may present with arthritis. [32]

The common pandemics of tuberculosis and HIV disproportionately affect populations in less resourced countries and are known to cause chronic or acute arthritis and joint pain in CYP, and as such, warrant mention. [33-35] In 2016, it was estimated that 2.1 million CYP are living with HIV and that over $80 \%$ of these CYP live in sub-Saharan Africa. [36] One million CYP around the world are infected with tuberculosis each year, with only $13 \%$ of eligible CYP receiving preventative treatment in 2016. [37] The statements also highlight malaria, brucellosis, and Chikungunya virus which occur with region-specific high prevalence and which may present with fever and arthritis, thus confounding the diagnosis of JIA and systemic JIA (especially in the context of macrophage activation syndrome) [38-42]. In addition, sickle cell disease, an inherited condition preferentially occurring in areas of high malaria prevalence, is a common mimic of arthritis and 
Table 2 Recommended time period between interruption of immunosuppressive therapy and administration of live vaccines

\begin{tabular}{|c|c|}
\hline Medication & Time period \\
\hline $\begin{array}{l}\text { High-dose systemic steroids ( } \geq 20 \mathrm{mg} \\
\text { per day of prednisone or equivalent } \\
\text { for }>2 \text { weeks) }\end{array}$ & Wait at least 1 month \\
\hline Methotrexate (>20 mg/week) & Wait at least 1 month \\
\hline $\begin{array}{l}\text { Azathioprine } \\
\text { Cyclosporine }\end{array}$ & Wait at least 3 months \\
\hline \multicolumn{2}{|l|}{ Cyclophosphamide } \\
\hline \multicolumn{2}{|l|}{ Mycophenolate mofetil } \\
\hline \multicolumn{2}{|l|}{ Tacrolimus } \\
\hline Human immunoglobulin & Wait at least 3 months \\
\hline Biologics agents & Wait at least 4 half-lives* \\
\hline Rituximab & Wait at least 12 months*** \\
\hline
\end{tabular}

As currently, no data are available, these recommendations are mostly based on expert opinion and medication half-lives

From: Heijstek MW, Ott de Bruin LM, Bijl M, Borrow R, van der Klis F, Kone-Paut I, et al. EULAR recommendations for vaccination in paediatricpediatric patients with rheumatic diseases. Ann Rheum Dis. 2011;70 [10]:1704-12

therefore included. [43-45] A number of infections, such as Zika and Chagas disease, were identified as concerns in the needs assessment but excluded by consensus based on lack of evidence of overlapping clinical symptoms. [46, 47]

The statements are also notable for their focus on the role of specific endemic diseases and how they may complicate treatment of JIA, an area of clinical management unexplored by existing recommendations. Familiarity with infections such as HIV, tuberculosis, and hepatitis B and their screening, prophylaxis, and treatment are of particular relevance to the management of CYP living with JIA in developing countries and who are treated with biologics or other immune suppression. Recognizing the importance of primary prophylaxis for communicable disease, our recommendations also endorse guidelines for vaccinations for children with rheumatic disease while recognizing that there may be issues of availability and specific disease risks that may require local adaptation of EULAR recommendations. [48-50] While significant inequities in immunization continue to exist around the world with coverage levels of some vaccines, e.g., measles, being

Table 3 Routine vaccinations, additional vaccinations (e.g., varicella), and an approach to catch-up vaccinations to advocate for pediatric rheumatology patients

\begin{tabular}{ll}
\hline Vaccine type & $\begin{array}{l}\text { Interval before starting } \\
\text { immune suppression }\end{array}$ \\
\hline Inactivated vaccines & 2 weeks \\
Lives vaccines & 4 weeks
\end{tabular}

Recommended time period between administration of live and killed vaccines and commencing immune suppression [79] too low still to prevent outbreaks or avert preventable deaths, [51] the statements address routine vaccinations, additional vaccinations (e.g., varicella), and an approach to catch-up vaccinations to advocate for pediatric rheumatology patients for whom, if immune suppressed, infections can pose a significant challenge (Tables 2 and 3).

\section{Treatment, referral, and monitoring}

Statements pertaining to treatment, referral, and monitoring emphasize and advocate for best practices in pediatric rheumatology currently used in many developed countries and recognized, through the needs assessment, as a challenge in developing nations. $[15-17,20]$ This inspired statements that encourage an agreed upon transition strategy for adolescents moving to adult-centered services; [52-55] specify a time frame within which a patient with suspected new inflammatory arthritis should be assessed by a pediatric rheumatologist in order to prevent joint damage [56-60] and endorse surveillance programs to identify JIA-associated uveitis. The latter was felt to be particularly important after $40 \%$ of respondents to the needs assessment cited that uveitis screening was not routinely done in their settings. [61-67] While no specific recommendations for the pharmaceutical management of JIA are proposed, a recommendation is made that pediatric pheumatologists consider and adapt existing treatment algorithms based on local needs and availability.

\section{Education}

The existence of specialist training units for pediatric rheumatologists is not likely to be a feasible goal in the near-tomedium-term in many LRC. The statements pertaining to education and education thus encourage collaboration, innovation, and sharing of knowledge and resources among the international community to strengthen knowledge of, and, inspire training in the care of CYP with JIA worldwide. Limited education and training opportunities in JIA among general and specialist medical and allied health curricula, as well as a lack of trained rheumatologists as teachers were concerns raised by up to $74 \%$ of practitioners who responded to the needs assessment survey (manuscript in progress). Our statements refer to freely available electronic resources such as 'paediatric musculoskeletal matters international' (http://www.pmmonline. org) as well as other online syllabi and training programs, to facilitate access to educational resources, networking, and collaborative opportunities. The statements also introduce strategies for individuals and institutions to incorporate core 'essential' teaching on JIA and pediatric musculoskeletal disease into health professions training. The importance of JIA education in undergraduate medical education is recognized in recommendations from the WHO and several national medical societies. [68-70] Furthermore, these 
statements describe different healthcare workers who could interact with a child with JIA in developing countries, and as such, describe how training in pediatric rheumatology and in delivery of JIA care in the LRC context differs from that of developed nations.

\section{Advocacy, networks, and policy}

Advocacy for access to appropriate care is especially important in countries where non-communicable diseases such as JIA have historically not received much attention. Involvement and engagement of CYP, families, and support networks in JIA awareness and support is a valuable component of comprehensive care of patients with JIA. [71, 72] Support and advocacy groups can play an important role in influencing healthcare policy makers and may include a number of stakeholders as well as involve a number of outlets such as media and public broadcasting. [73] Reference to advocacy and education campaigns are alluded to in the statements and their references as well; these are meant to serve as a signpost to others seeking strategies to raise the profile of JIA in their local settings.

\section{Research}

The consensus group agrees that the particular difficulties in managing JIA in specific populations can only improve by the conduct of appropriate research. Ideally, research projects should be initiated locally and be driven by local needs. Statements in this section are aimed at encouraging these principles, including training in research for local investigators, while also encouraging collaboration between national and regional partners, as well as globally. [74] Although the issue of clinical trials for JIA therapies in LRCs was not raised in the needs assessment study and is therefore not included in the current statements, the consensus group felt that there is a need to address this unmet need in future iterations of these recommendations. Because of new pediatric legislation in Europe and North America, it is now customary that industrysponsored clinical trials with new medications involve centers in LRC. [75] This caveat exists due to the extensive availability of biologic agents in more resourced countries, making enrollment in clinical trials there more difficult. The members of the consensus group support the ethical requirements of the PRINTO and Pediatric Rheumatology Collaborative Study Group (PRCSG) which now require pharmaceutical companies conducting trials in LRC to continue to provide the drug until benefit is seen in a child's clinical response, or, until an alternative method of drug provision is identified and funding secured. Indeed as reported by Ruperto et al. [75], trial participation from Latin America and Eastern Europe is becoming increasingly more important for successful completion of enrolment in a timely manner. The PRINTO/PRCSG leaderships have in the past demanded a written commitment from pharmaceutical companies, to provide the drug until approval for JIA in the participating country. This was, however, insufficient protection to low-income populations. There was strong agreement that companies continue to provide post-trial access to therapy until the patient no longer requires it.

\section{Discussion}

The development of recommendations appropriate for LRC is a novel project in the field of pediatric rheumatology. Bringing experienced clinicians and academics from Europe and North America together with pediatric rheumatology care providers from LRC who are developing services unique to their own environments, is a pragmatic model aiming to build on existing knowledge and experience to deliver recommendations "fit for purpose". This project has grown from the emergence of pediatric rheumatology services in less resourced countries in the context of inequalities in global healthcare and burdens of disease, as well as a recognition that similar recommendations for other settings do not adequately serve all patients with JIA.

These recommendations address notable discrepancies relevant to the management of JIA in developing nations: they highlight endemic diseases relevant to less resourced nations and endorse existing guidelines, where possible, for the treatment of JIA; vaccinations in the context of rheumatic disease; and, uveitis screening. They also advocate for standards of care when accessing pediatric rheumatology services; introduce strategies to raise awareness of JIA targeting policy makers, the general public, education and training workforce, and healthcare practitioners; and make arguments to support and development of research and researcher capacity in JIA in LRC.

\section{Strengths}

This is the first paper to our knowledge to address challenges specific to the care of CYP with JIA in developing countries. It is based on a thorough needs assessment that received responses from over 100 practitioners involved in pediatric rheumatology around the world, representing over 25 developing countries (manuscript in progress). These recommendations create a vision as well as provide specific frameworks for care for CYP with JIA in LRC. They make reference to existing recommendations, provide a platform to build on existing knowledge, and to stimulate new areas of research and endeavor. The emphasis on communicable and endemic diseases influencing the diagnosis and treatment of JIA in our recommendations is both timely and relevant, given the influences of climate change, global travel, and migration. Even within developed countries, certain populations experience significant health disparities for which a clinician must be 
astute and consider issues such as endemic infections previously thought only relevant to LRC in their diagnostic workup, such as acute rheumatic fever and Tuberculosis. In addition, many developed countries still have a shortage of pediatric rheumatologists with underrepresentation of pediatric rheumatology in many programs of undergraduate and postgraduate medical training as well as other health professions training. These recommendations, as such, have global applicability not only in the realm of clinical practice, but also in health professions education, advocacy, and research.

\section{Limitations}

While many more countries and representatives in the realm of pediatric rheumatology could have been involved in the drafting of these recommendations, the individuals who were selected to participate were chosen as they had a vested interest and commitment to the progress and development of pediatric rheumatology in LRC as well as experience in the development of standards of care at national and international levels. The authors recognize that the involvement of other stakeholders in the care of CYP with JIA including families, allied health practitioners, general practitioners, and pediatricians, would have added to the methodological rigor of this project; this includes both the needs assessment as well as the drafting of statements. Such individuals are expected to participate in future iterations of such recommendations. For this first iteration, and for purposes of practicality, the working group decided to first gain consensus among a small, but heterogenous group of pediatric rheumatology clinicians. These statements are meant to serve as a working document, and, as such the authors expect that they will change with time, as well as with advancements in knowledge, technology and of course, development in LRCs. The recommendations are also not meant to be exhaustive and those utilizing them should continue to apply their knowledge of local healthcare contexts in the care of CYP with JIA. Finally, the authors acknowledge that many other social determinants of health affect access to care, with an ongoing need for raising standards of health on a more holistic level in order for there to be seamless access to and provision of care for children with JIA.

There has been rapid progress in the management of JIA in developing countries and the evidence base for interventions such as pharmaceuticals and vaccinations are of great relevance to all children with JIA, though they may be influenced by the unique and varied environments in which they live. For this reason, these recommendations are not seen as a replacement of other recommendations, but as a supplement to them. This is acknowledged by referring to known and agreed upon evidence-based recommendations, as further research and advances will inevitably lead to changes and modifications in the future. New information and a growing body of work emanating from LRC will enable future revisions of these statements.

\section{Conclusion}

These recommendations present principles encouraging the development and support of pediatric rheumatology in LRC in a move towards "rheumatology without borders" [76]: the provision and access to rheumatology education, innovation, discovery, and care for all around the world. Our recommendations offer novel insights into the challenges facing LRC and present consensus-based strategies for the management of JIA in these health care contexts. With increasing globalization, these recommendations - as a whole - provide educational and clinical applicability for clinicians worldwide. Patient, allied health, and generalist physician input would also be valuable to future versions of these recommendations to allow for perspectives of all stakeholders to be represented. There is a need for targeted trials specifically designed to involve LRC where costly biologic medications currently have limited availability. The low evidence base for our recommendations is an impetus for further collaborative inquiry among health professionals in less resourced countries together with guidance from experienced networks such as PRINTO to optimize care for children with JIA in developing nations and around the world.

Funding information The research was conducted using funding from an International Leagues of Associations for Rheumatology (ILAR) Grant.

\section{Compliance with ethical standards}

Disclosures None.

\section{References}

1. Petty RE, Southwood TR, Manners P, Baum J, Glass DN, Goldenberg J, He X, Maldonado-Cocco J, Orozco-Alcala J, Prieur AM, SuarezAlmazor ME, Woo P, International League of Associations for Rheumatology (2004) International league of associations for rheumatology classification of juvenile idiopathic arthritis: second revision, Edmonton, 2001. J Rheumatol 31(2):390-392

2. Crisp N (2011) Global health capacity and workforce development: turning the world upside down. Infect Dis Clin N Am 25(2):359-367

3. (2017) Global, regional, and national age-sex specific mortality for 264 causes of death, 1980-2016: a systematic analysis for the Global Burden of Disease Study 2016. Lancet;390(10100):1151-210

4. Denno D (2011) Global child health. Pediatr Rev 32(2):e25-e38

5. Henrickson M (2011) Policy challenges for the pediatric rheumatology workforce: Part III the international situation. Pediatr Rheumatol Online J 9:26

6. Manners PJ, Bower C (2002) Worldwide prevalence of juvenile arthritis why does it vary so much? J Rheumatol 29(7):1520-1530

7. Manners PJ, Diepeveen DA (1996) Prevalence of juvenile chronic arthritis in a population of 12-year-old children in urban Australia. Pediatrics 98(1):84-90

8. United Nations Chidlrens Fund (UNICEF) 2017 State of the World's Children Report: [Available from: https://data.unicef.org/

9. Arkachaisri T, Tang SP, Daengsuwan T, Phongsamart G, Vilaiyuk S, Charuvanij S, Hoh SF, Tan JH, Das L, Ang E, Lim W, Chan YH, 
Bernal CB, Asia Pacific Pediatric Rheumatology Education and Research Network (2017) Paediatric rheumatology clinic population in Southeast Asia: are we different? Rheumatology (Oxford) 56(3):390-398

10. Gibson T (2015) Rheumatology in India and Pakistan today. Rheumatology (Oxford) 54(5):753-754

11. Scott C, Webb K (2014) Paediatric rheumatology in sub-Saharan Africa. Rheumatology (Oxford) 53(8):1357-1358

12. Ruperto N, Martini A (2011) Networking in paediatrics: the example of the Paediatric rheumatology international trials organisation (PRINTO). Arch Dis Child 96(6):596-601

13. Consolaro A, Dolezalova P, Panaviene V, Christensen AE, Merino R, Constantin T, Martini A, Ravelli A, EPOCA study group (2014) A multinational study of the epidemiology, treatment and outcome of childhood arthritis (epoca study): preliminary data from 6,940 patients. Pediatr Rheumatol 12(1):O8

14. Consolaro A, Ruperto N, Filocamo G, Lanni S, Bracciolini G, Garrone M, Scala S, Villa L, Silvestri G, Tani D, Zolesi A, Martini A, Ravelli A, for the Pediatric Rheumatology International Trials Organization (PRINTO) (2012) Seeking insights into the EPidemiology, treatment and outcome of childhood arthritis through a multinational collaborative effort: introduction of the EPOCA study. Pediatr Rheumatol Online J 10(1):39

15. Beukelman T, Patkar NM, Saag KG, Tolleson-Rinehart S, Cron RQ, DeWitt EM et al (2011) 2011 American College of Rheumatology recommendations for the treatment of juvenile idiopathic arthritis: initiation and safety monitoring of therapeutic agents for the treatment of arthritis and systemic features. Arthritis Care Res (Hoboken) 63(4):465-482

16. Davies K, Cleary G, Foster H, Hutchinson E, Baildam E (2010) BSPAR standards of care for children and young people with juvenile idiopathic arthritis. Rheumatology (Oxford) 49(7):1406-1408

17. Munro J, Murray K, Boros C, Chaitow J, Allen RC, Akikusa J, Adib N, Piper SE, Singh-Grewal D, Australian Paediatric Rheumatology Group (2014) Australian Paediatric rheumatology group standards of care for the management of juvenile idiopathic arthritis. J Paediatr Child Health 50(9):663-666

18. Cellucci T, Guzman J, Petty RE, Batthish M, Benseler SM, Ellsworth JE et al (2016) Management of Juvenile Idiopathic Arthritis 2015: a position statement from the pediatric Committee of the Canadian Rheumatology Association. J Rheumatol 43(10): 1773-1776

19. Constantin T, Foeldvari I, Anton J, de Boer J, Czitrom-Guillaume S, Edelsten $\mathrm{C}$ et al (2018) Consensus-based recommendations for the management of uveitis associated with juvenile idiopathic arthritis: the SHARE initiative. Ann Rheum Dis:annrheumdis-2018-213131

20. Ravelli A, Consolaro A, Horneff G, Laxer RM, Lovell DJ, Wulffraat NM, Akikusa JD, al-Mayouf SM, Antón J, Avcin T, Berard RA, Beresford MW, Burgos-Vargas R, Cimaz R, de Benedetti F, Demirkaya E, Foell D, Itoh Y, Lahdenne P, Morgan EM, Quartier P, Ruperto N, Russo R, Saad-Magalhães C, Sawhney S, Scott C, Shenoi S, Swart JF, Uziel Y, Vastert SJ, Smolen JS (2018) Treating juvenile idiopathic arthritis to target: recommendations of an international task force. Ann Rheum Dis 77(6):819-828

21. Giannini EH, Brewer EJ, Kuzmina N, Shaikov A, Maximov A, Vorontsov I, Fink CW, Newman AJ, Cassidy JT, Zemel LS (1992) Methotrexate in resistant juvenile rheumatoid arthritis. Results of the U.S.a.-U.S.S.R. double-blind, placebo-controlled trial. The pediatric rheumatology collaborative study group and the cooperative Children's study group. N Engl J Med 326(16):1043-1049

22. Ruperto N, Murray KJ, Gerloni V, Wulffraat N, de Oliveira SK, Falcini $\mathrm{F}$ et al (2004) A randomized trial of parenteral methotrexate comparing an intermediate dose with a higher dose in children with juvenile idiopathic arthritis who failed to respond to standard doses of methotrexate. Arthritis Rheum 50(7):2191-2201
23. Foell D, Wulffraat N, Wedderburn LR, Wittkowski H, Frosch M, Gerss J, Stanevicha V, Mihaylova D, Ferriani V, Tsakalidou FK, Foeldvari I, Cuttica R, Gonzalez B, Ravelli A, Khubchandani R, Oliveira S, Armbrust W, Garay S, Vojinovic J, Norambuena X, Gamir ML, García-Consuegra J, Lepore L, Susic G, Corona F, Dolezalova P, Pistorio A, Martini A, Ruperto N, Roth J, Paediatric Rheumatology International Trials Organization (PRINTO) (2010) Methotrexate withdrawal at 6 vs 12 months in juvenile idiopathic arthritis in remission: a randomized clinical trial. JAMA 303(13):1266-1273

24. Ruperto N, Lovell DJ, Quartier P, Paz E, Rubio-Perez N, Silva CA et al (2010) Long-term safety and efficacy of abatacept in children with juvenile idiopathic arthritis. Arthritis Rheum 62(6):1792-1802

25. De Benedetti F, Brunner HI, Ruperto N, Kenwright A, Wright S, Calvo I et al (2012) Randomized trial of tocilizumab in systemic juvenile idiopathic arthritis. N Engl J Med 367(25):2385-2395

26. Ruperto N, Brunner HI, Quartier P, Constantin T, Wulffraat N, Horneff G, Brik R, McCann L, Kasapcopur O, Rutkowska-Sak L, Schneider R, Berkun Y, Calvo I, Erguven M, Goffin L, Hofer M, Kallinich T, Oliveira SK, Uziel Y, Viola S, Nistala K, Wouters C, Cimaz R, Ferrandiz MA, Flato B, Gamir ML, Kone-Paut I, Grom A, Magnusson B, Ozen S, Sztajnbok F, Lheritier K, Abrams K, Kim D, Martini A, Lovell DJ, PRINTO, PRCSG (2012) Two randomized trials of canakinumab in systemic juvenile idiopathic arthritis. N Engl J Med 367(25):2396-2406

27. Brunner HI, Ruperto N, Zuber Z, Keane C, Harari O, Kenwright A, Lu P, Cuttica R, Keltsev V, Xavier RM, Calvo I, Nikishina I, RubioPérez N, Alexeeva E, Chasnyk V, Horneff G, Opoka-Winiarska V, Quartier P, Silva CA, Silverman E, Spindler A, Baildam E, Gámir ML, Martin A, Rietschel C, Siri D, Smolewska E, Lovell D, Martini A, de Benedetti F, Paediatric Rheumatology International Trials Organisation PRINTO, Pediatric Rheumatology Collaborative Study Group (PRCSG) (2015) Efficacy and safety of tocilizumab in patients with polyarticular-course juvenile idiopathic arthritis: results from a phase 3, randomised, double-blind withdrawal trial. Ann Rheum Dis 74(6):1110-1117

28. Brunner HI, Ruperto N, Tzaribachev N, Horneff G, Chasnyk VG, Panaviene V, Abud-Mendoza C, Reiff A, Alexeeva E, Rubio-Pérez N, Keltsev V, Kingsbury DJ, del Rocio Maldonado Velázquez M, Nikishina I, Silverman ED, Joos R, Smolewska E, Bandeira M, Minden K, van Royen-Kerkhof A, Emminger W, Foeldvari I, Lauwerys BR, Sztajnbok F, Gilmer KE, Xu Z, Leu JH, Kim L, Lamberth SL, Loza MJ, Lovell DJ, Martini A, Paediatric Rheumatology International Trials Organisation (PRINTO) and the Pediatric Rheumatology Collaborative Study Group (PRCSG) (2018) Subcutaneous golimumab for children with active polyarticular-course juvenile idiopathic arthritis: results of a multicentre, double-blind, randomised-withdrawal trial. Ann Rheum Dis 77(1):21-29

29. El Zorkany B, Alwahshi HA, Hammoudeh M, Al Emadi S, Benitha R, Al Awadhi A et al (2013) Suboptimal management of rheumatoid arthritis in the Middle East and Africa: could the EULAR recommendations be the start of a solution? Clin Rheumatol 32(2):151-159

30. Harris PA, Taylor R, Thielke R, Payne J, Gonzalez N, Conde JG (2009) Research electronic data capture (REDCap)-a metadatadriven methodology and workflow process for providing translational research informatics support. J Biomed Inform 42(2):377-381

31. Delbecq AL Van de Ven AH, Gustafson DH. (1975) Group Techniques for Program Planning: A guide to nominal group and Delphi processes,. 1 ed: Foresman and company

32. World Health Organisation(WHO) (2018) Climate Change And Infectious Diseases: [Available from: http://www.who.int/ globalchange/environment/en/chapter6.pdf

33. Held MFG, Hoppe S, Laubscher M, Mears S, Dix-Peek S, Zar HJ, Dunn RN (2017) Epidemiology of musculoskeletal tuberculosis in an area with high disease prevalence. Asian Spine J 11(3):405-411 
34. Sharma A, Pinto B, Dogra S, Sharma K, Goyal P, Sagar V, Dhir V, Sharma S, Singh S (2016) A case series and review of Poncet's disease, and the utility of current diagnostic criteria. Int J Rheum Dis 19(10): 1010-1017

35. Chinniah K, Mody GM, Bhimma R, Adhikari M (2005) Arthritis in association with human immunodeficiency virus infection in black African children: causal or coincidental? Rheumatology (Oxford) 44(7):915-920

36. UNAIDS (2016) People Living with HIV [Available from: http:// aidsinfo.unaids.org/).

37. Childhood Tuberculosis: World Health Organisation(WHO) 2017 [Available from: http://www.who.int/tb/areas-of-work/children/en/

38. Arevalo-Herrera M, Lopez-Perez M, Medina L, Moreno A, Gutierrez JB, Herrera S (2015) Clinical profile of plasmodium falciparum and plasmodium vivax infections in low and unstable malaria transmission settings of Colombia. Malar J 14:154

39. Murray CJ, Ortblad KF, Guinovart C, Lim SS, Wolock TM, Roberts DA et al (2014) Global, regional, and national incidence and mortality for HIV, tuberculosis, and malaria during 1990-2013: a systematic analysis for the Global Burden of Disease Study 2013. Lancet 384(9947): 1005-1070

40. Samra JA, Hagood NL, Summer A, Medina MT, Holden KR (2017) Clinical features and neurologic complications of children hospitalized with chikungunya virus in Honduras. J Child Neurol 32(8):712-716

41. Kumar A, Best C, Benskin G (2017) Epidemiology, clinical and laboratory features and course of chikungunya among a cohort of children during the first Caribbean epidemic. J Trop Pediatr 63(1):43-49

42. Kajeguka DC, Kaaya RD, Mwakalinga S, Ndossi R, Ndaro A, Chilongola JO, Mosha FW, Schiøler KL, Kavishe RA, Alifrangis M (2016) Prevalence of dengue and chikungunya virus infections in North-Eastern Tanzania: a cross sectional study among participants presenting with malaria-like symptoms. BMC Infect Dis 16:183

43. Vanderhave KL, Perkins CA, Scannell B, Brighton BK (2018) Orthopaedic manifestations of sickle cell disease. J Am Acad Orthop Surg 26(3):94-101

44. Vaishya R, Agarwal AK, Edomwonyi EO, Vijay V (2015) Musculoskeletal manifestations of sickle cell disease: a review. Cureus 7(10):e358

45. Zuhlke LJ, Beaton A, Engel ME, Hugo-Hamman CT, Karthikeyan G, Katzenellenbogen JM et al (2017) Group a Streptococcus, acute rheumatic fever and rheumatic heart disease: epidemiology and clinical considerations. Curr Treat Options Cardiovasc Med 19(2):15

46. Karwowski MP, Nelson JM, Staples JE, Fischer M, Fleming-Dutra KE, Villanueva J, Powers AM, Mead P, Honein MA, Moore CA, Rasmussen SA (2016) Zika virus disease: a CDC update for pediatric health care providers. Pediatrics 137(5):e20160621

47. Rassi A Jr, Rassi A, Marcondes de Rezende J (2012) American trypanosomiasis (Chagas disease). Infect Dis Clin N Am 26(2): 275-291

48. Groot N, Heijstek MW, Wulffraat NM (2015) Vaccinations in paediatric rheumatology: an update on current developments. Curr Rheumatol Rep 17(7):46

49. Heijstek MW, Ott de Bruin LM, Bijl M, Borrow R, van der Klis F, Kone-Paut I et al (2011) EULAR recommendations for vaccination in paediatric patients with rheumatic diseases. Ann Rheum Dis 70(10):1704-1712

50. Kobayashi I, Mori M, Yamaguchi K, Ito S, Iwata N, Masunaga K, Shimojo N, Ariga T, Okada K, Takei S (2015) Pediatric rheumatology Association of Japan recommendation for vaccination in pediatric rheumatic diseases. Mod Rheumatol 25(3):335-343

51. United Nations Childrens Fund(UNICEF)/World Health Organisation(WHO) (2016) 1 in 10 infants worldwide did not receive any vaccinations in 2016: [Available from: $\mathrm{http}: / / \mathrm{www} . w h o$. $\mathrm{int} /$ mediacentre/news/releases/2017/infants-worldwidevaccinations/en/
52. Anelli CG, Amorim ALM, Osaku FM, Terreri MT, Len CA, Reiff A (2017) Challenges in transitioning adolescents and young adults with rheumatologic diseases to adult Care in a Developing Country - the Brazilian experience. Pediatr Rheumatol Online J 15(1):47

53. Cooley WC, Sagerman PJ (2011) Supporting the health care transition from adolescence to adulthood in the medical home. Pediatrics 128(1):182-200

54. Foster HE, Minden K, Clemente D, Leon L, McDonagh JE, Kamphuis S et al (2017) EULAR/PReS standards and recommendations for the transitional care of young people with juvenile-onset rheumatic diseases. Ann Rheum Dis 76(4):639-646

55. Robertson L (2006) When should young people with chronic rheumatic disease move from paediatric to adult-centred care? Best Pract Res Clin Rheumatol 20(2):387-397

56. Foster HE, Eltringham MS, Kay LJ, Friswell M, Abinun M, Myers A (2007) Delay in access to appropriate care for children presenting with musculoskeletal symptoms and ultimately diagnosed with juvenile idiopathic arthritis. Arthritis Rheum 57(6):921-927

57. Foster H, Rapley T, May C (2010) Juvenile idiopathic arthritis: improved outcome requires improved access to care. Rheumatology (Oxford) 49(3):401-403

58. Tzaribachev N, Benseler SM, Tyrrell PN, Meyer A, KuemmerleDeschner JB (2009) Predictors of delayed referral to a pediatric rheumatology center. Arthritis Rheum 61(10):1367-1372

59. Aoust L, Rossi-Semerano L, Kone-Paut I, Dusser P (2017) Time to diagnosis in juvenile idiopathic arthritis: a french perspective. Orphanet J Rare Dis 12(1):43

60. Albers HM, Wessels JA, van der Straaten RJ, Brinkman DM, Suijlekom-Smit LW, Kamphuis SS, Girschick HJ, Wouters C, Schilham MW, le Cessie S, Huizinga TW, ten Cate R, Guchelaar HJ (2009) Time to treatment as an important factor for the response to methotrexate in juvenile idiopathic arthritis. Arthritis Rheum 61(1):46-51

61. Anesi SD, Foster CS (2012) Importance of recognizing and preventing blindness from juvenile idiopathic arthritis-associated uveitis. Arthritis Care Res (Hoboken). 64(5):653-657

62. Bou R, Adan A, Borras F, Bravo B, Calvo I, De Inocencio J et al (2015) Clinical management algorithm of uveitis associated with juvenile idiopathic arthritis: interdisciplinary panel consensus. Rheumatol Int 35(5):777-785

63. Edelsten C, Lee V, Bentley CR, Kanski JJ, Graham EM (2002) An evaluation of baseline risk factors predicting severity in juvenile idiopathic arthritis associated uveitis and other chronic anterior uveitis in early childhood. Br J Ophthalmol 86(1):51-56

64. Gregory AC, 2nd, Kempen JH, Daniel E, Kacmaz RO, Foster CS, Jabs DA, et al. Risk factors for loss of visual acuity among patients with uveitis associated with juvenile idiopathic arthritis: the systemic immunosuppressive therapy for eye diseases study. Ophthalmology 2013;120(1):186-192

65. Heiligenhaus A, Niewerth M, Ganser G, Heinz C, Minden K (2007) Prevalence and complications of uveitis in juvenile idiopathic arthritis in a population-based nation-wide study in Germany: suggested modification of the current screening guidelines. Rheumatology (Oxford) 46(6):1015-1019

66. Saurenmann RK, Levin AV, Feldman BM, Laxer RM, Schneider R, Silverman ED (2010) Risk factors for development of uveitis differ between girls and boys with juvenile idiopathic arthritis. Arthritis Rheum 62(6):1824-1828

67. Saurenmann RK, Levin AV, Feldman BM, Rose JB, Laxer RM, Schneider R, Silverman ED (2007) Prevalence, risk factors, and outcome of uveitis in juvenile idiopathic arthritis: a long-term followup study. Arthritis Rheum 56(2):647-657

68. Jandial S, Stewart J, Foster HE (2015) What do they need to know: achieving consensus on paediatric musculoskeletal content for medical students. BMC Med Educ 15:171 
69. Wadey VM, Tang ET, Abelseth G, Dev P, Olshen RA, Walker D (2007) Canadian multidisciplinary core curriculum for musculoskeletal health. J Rheumatol 34(3):567-580

70. Woolf AD, Walsh NE, Akesson K (2004) Global core recommendations for a musculoskeletal undergraduate curriculum. Ann Rheum Dis 63(5):517-524

71. Tong A, Jones J, Speerin R, Filocamo K, Chaitow J, Singh-Grewal D (2013) Consumer perspectives on pediatric rheumatology care and service delivery: a qualitative study. J Clin Rheumatol 19(5): 234-240

72. Stinson J, Ahola Kohut S, Forgeron P, Amaria K, Bell M, Kaufman M, Luca N, Luca S, Harris L, Victor C, Spiegel L (2016) The iPeer2Peer program: a pilot randomized controlled trial in adolescents with juvenile idiopathic arthritis. Pediatr Rheumatol Online J. 14(1):48

73. Chipeta J, Njobvu P, McGill PE, Bucala R (2014) Progress made towards enhancement of rheumatology education and practice in Zambia: review of an ILAR-supported project. Clin Rheumatol 33(10):1367-1372
74. Colmegna I, Bartlett SJ, Oyoo OG (2011) The ILAR-East Africa initiative: current needs and progress in the globalization of rheumatology. Clin Rheumatol 30(2):251-253

75. Ruperto N, Vesely R, Saint-Raymond A, Martini A (2013) Paediatric rheumatology international trials O. impact of the European paediatric legislation in paediatric rheumatology: past, present and future. Ann Rheum Dis 72(12):1893-1896

76. Lau CS, Feng PH (2007) Rheumatology without borders. Nat Clin Pract Rheumatol 3(6):305

77. 2018 Recommended Immunizations For Infants and Children (Birth through 6 Years): Centers for Disease Control and Prevention; 2018 [Available from: https://www.cdc.gov/vaccines/ schedules/easy-to-read/child-easyread.html

78. Summary of WHO Position Papers - Recommended Routine Immunizations for Children: World Health Organisation(WHO); 2018 [Available from: http://www.who.int/immunization/policy/ Immunization_routine_table2.pdf?ua $=1$

79. Moore DL (2018) Immunization of the immunocompromised child: key principles. Paediatr Child Health 23(3):203-205 